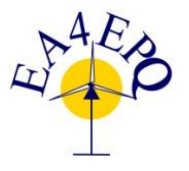

International Conference on Renewable Energies and Power Quality (ICREPQ'13)

Bilbao (Spain), $20^{\text {th }}$ to $22^{\text {th }}$ March, 2013

Premourable Éncrigy and. Promer Quatily foumal (RE\&PQJ)

ISSN 2172-038 X, No.11, March 2013

\title{
Conducting Organic Polymers Modified by Incorporation of Semiconductor (POC/SM) - Synthesis and Electrochemical characterization of composite materials
}

\author{
B. NESSARK ${ }^{*}(\mathbf{a})$, S. ABACI ${ }^{(\mathbf{a})}$, F. HABELHAMES $^{(\mathbf{a})}$, L. LAMIRI $^{(\mathbf{a})}$, K. LMIMOUNI $^{(\mathbf{b})}$ \\ *Laboratoire d'Electrochimie et Matériaux, Département de Génie des Procédés, \\ Faculté de Technologie, Université Ferhat-Abbas de Sétif, 19000 Sétif.
}

Fax: (+213) 369251 33, Tel : (+213) 7744234 68, E-mail: b.nessark@yahoo.Fr

**Université des Sciences et Technologies de Lille, IEMN-UMR CNRS 8520, BP 60069 avenue Poincaré, 59652 Villeneuve d'Ascq Cedex, France

\begin{abstract}
.
This study consists of the analysis of the electrochemical and electronic properties, polyaniline for their use as electrode materials in electrochemical and electronic applications. The polymerization of the monomer was carried out on platinum $(\mathrm{Pt})$ or indium tin oxide (ITO). The study was carried out by voltamperometry cyclic, electrochemical impedance spectroscopy (EIS). The dispersion of oxide semiconductors $\left(\mathrm{TiO}_{2}, \mathrm{MnO}_{2}\right)$ in the polymer matrix was also used to improve the electronic and electrochemical properties.

This present study can be regarded as an invaluable contribution in search of composite materials having of high efficiencies which being able to be used as active electrode materials in the design of electronic components and as active materials in the photovoltaic cells and electrochemical generators.
\end{abstract}

\section{Keywords}

polyaniline, conductive organic polymers, composite material, cyclic voltamperometry, electrochemical impedance spectroscopy.

\section{Introduction}

Conducting polymers resulting from the pyrrole, thiophene, aniline and their derivatives have a special place in the search because of their stability and for their gap near to that of the usual semiconductors. The performances of these conducting organic polymers as electrode materials were shown in diverse applications: electrochemical generators (fuel cells, batteries) [1], électrocatalysis $[2,3]$, photovoltaic cell, storage and conversion of energy, light emitting diodes, field effect transistor [4-6].

More recently, new areas of application of classified conductive organic polymers as the fight against corrosion, modified electrodes, microelectronics have led the 
electrochemists to interest this class of molecular materials [7].

The use of organic polymers semiconductors, in electronic and electrochemical applications presents several advantages. One the one hand, the ease and speed of manufacturing process simple and inexpensive and allow to consider the development of flexible large-area devices. On the other hand, the optical and electronic properties of organic polymers can be easily modulated, paving the way for development of devices covering the whole range of wavelengths of the visible spectrum. The materials used are conjugated polymers alternating with single bonds $(\sigma)$ and double $(\pi)$ generating a highly delocalized $\pi$ electrons, the origin of electronic and electrochemical properties. Among which we can mentioned polyacetylene (PA), paraphenylene (PPp), Polyaniline (PAn), polypyrrole (PPy) and polythiophene (PTh).

The interest of conductive organic polymers is twofold: it is both theoretical because of their special electronic properties and experimental due its multiple possibilities of functionalization. However, details of the electrochemical process is not fully controlled and still debated, due to the electrochemical behavior unconventional.

With the exception of polyacetylene (PA), all other conductive organic polymers can be produced electrochemically by anodic oxidation, unlike chemical methods, the films of conductive organic polymers are formed directly on the electrode this encouraged us to study the electrosynthesis and analyze the properties of the Polyaniline (PAn) modified by incorporation oxide $\left(\mathrm{TiO}_{2}\right.$ or $\mathrm{MnO}_{2}$ ) nanoparticles.

\section{Experimental}

This study consists of the analysis of the electrochemical and electronic properties of polyaniline for their use as electrode materials in electrochemical and electronic applications. The polymerization of the monomer was carried out on metal electrodes: platinum $(\mathrm{Pt})$, indium and tin oxyde (ITO). The study was carried out by voltamperometry cyclic, electrochemical impedance spectroscopy (EIS), UV-visible. The dispersion of oxide semiconductors $\left(\mathrm{TiO}_{2}, \mathrm{MnO}_{2}\right)$ in the polymer matrix was also used to improve the electronic and electrochemical properties. In the case of their use as electrode materials, tests of charge/discharge were carried out to determine the capacity and life of the generators.

\section{Results and discussion}

\section{1) Electrochemical behaviour of polyaniline on a Pt electrode (PAn/Pt)}

Figure 1 shows the cyclic voltammograms relating to the polyaniline/Pt, analyzed in $\mathrm{H}_{2} \mathrm{O} /\left(\mathrm{LiClO}_{4}\right.$ $0.1 \mathrm{M}+\mathrm{H}_{2} \mathrm{SO}_{4} 0.5 \mathrm{M}$ ) solution, obtained at $\mathrm{v}=10 \mathrm{mV} / \mathrm{s}$ between -0.2 and 0.9 V/SCE, on a platinum electrode $(\varnothing=2$ $\mathrm{mm})$. The polyaniline is obtained on a platinum electrode, by successive scanning potential (cycling) from a monomer solution at a concentration $10^{-1} \mathrm{M}$.

As shown, cyclic voltammograms reveal three anodic peaks during the potential positive scan and three cathodic peaks when scanning negatively. As scown, the intensity of oxidation and reduction peaks of the polymer film decreases slightly during the successive potential scan, it stabilizes after several cycles. Also, the potentials of oxidation peaks shifts to more positive values and the potentials of reduction peaks to more negative values. The intensity of the current is changing, more weakly in the opposite direction to what has been observed in the presence of the monomer. 


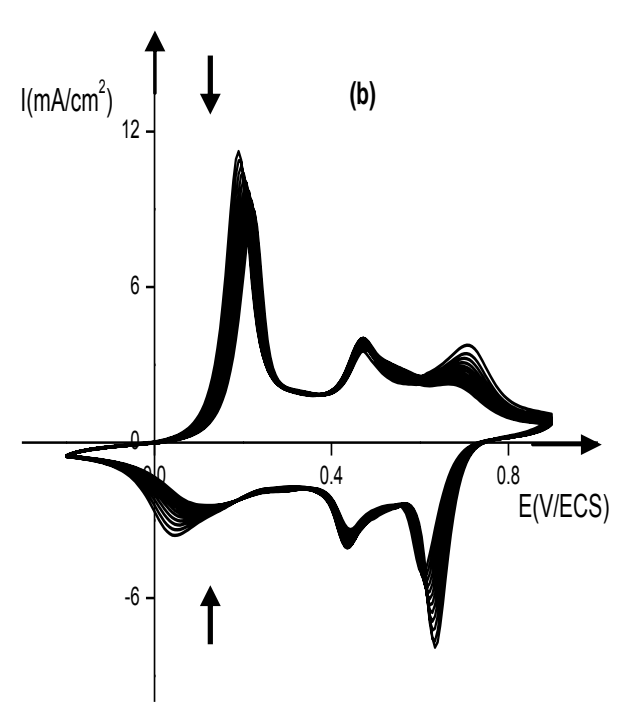

Figure 1: Cyclic voltammograms relating to polyaniline $(\mathrm{PAn} / \mathrm{Pt})$, in $\mathrm{H}_{2} \mathrm{O} /\left[\mathrm{LiClO}_{4}\right.$ $\left.(0.1 \mathrm{M})+\mathrm{H}_{2} \mathrm{SO}_{4}(0.5 \mathrm{M})\right]$ solution, obtained at $\mathrm{v}=10 \mathrm{mV} / \mathrm{s}$, between $-0,2$ et $0,9 \mathrm{~V} / \mathrm{SCE}$.

\section{2) Effect of the $\mathrm{pH}$ of the solution:}

The figure 2 shows the Nyquist diagrams relating to a platinum electrode modified by polyaniline film, obtained for different values of $\mathrm{pH}$ of the solution. The $\mathrm{pH}$ variation is obtained by dosage the solution $\mathrm{H}_{2} \mathrm{O} /\left(\mathrm{LiClO}_{4} 0,1 \mathrm{M}+\mathrm{H}_{2} \mathrm{SO}_{4} 0,5\right.$ $\mathrm{M}+\mathrm{An} 2.10^{-1} \mathrm{M}$ ) with a solution of $\mathrm{NaOH}$ $1 \mathrm{M}$. The film is analyzed in an aqueous solution $\left(\mathrm{H}_{2} \mathrm{SO}_{4} 0.5 \mathrm{M}+\mathrm{LiClO}_{4} 0.1 \mathrm{M}\right)$. The curves were recorded on a frequency range between $10^{5} \mathrm{~Hz}$ and $10^{-1} \mathrm{~Hz}$, with a disturbance of $10 \mathrm{mV}$, obtained at the open circuit potential $E_{\text {ocp }}$ which, it varies with the $\mathrm{pH}$ of the solution.

We note that the diagram is made towards the frequencies a semicircle which is characteristic of a charge transfer process, followed at low frequencies by a straight line characteristic of a diffusional process. The diameter of the semicircle increases with increasing $\mathrm{pH}$. The slopes of lines obtained at low frequencies are the same; this shows that the diffusion is governed by the same process.

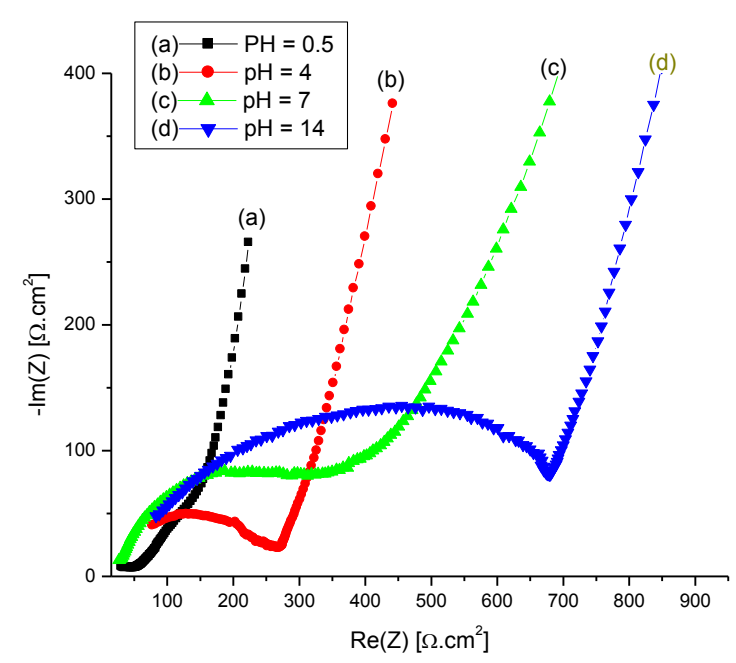

Figure 2: Nyquist diagrams related to the films of $\mathrm{PAn} / \mathrm{Pt}$, obtained for different values of the $\mathrm{pH}$ of the solution: $\mathrm{H}_{2} \mathrm{O} /\left(\mathrm{LiClO}_{4} 0.1 \mathrm{M}+\mathrm{H}_{2} \mathrm{SO}_{4} 0.5 \mathrm{M}+\mathrm{An}\right.$ $2.10^{-1} \mathrm{M}+\mathrm{NaOH} 1 \mathrm{M}$ ), and analyzed in a solution without monomer.

\section{3) Characterization of the composite $\left(\mathbf{P A n}+\mathrm{TiO}_{2}\right)$}

The figure 3 shows Nyquist diagrams relating to an electrode Polyaniline/Pt and the composite material $\left(\mathrm{PAn}+\mathrm{TiO}_{2}\right) / \mathrm{Pt}$ obtained from an aqueous solution $\left(\mathrm{H}_{2} \mathrm{SO}_{4} 0.5 \mathrm{M}+\mathrm{LiClO}_{4} 0.1 \mathrm{M}\right)$, containing the aniline monomer and as titanium oxide, held in suspension by agitation. The film is obtained for different concentrations of titanium oxide. The curves were recorded on a frequency range between $10^{5} \mathrm{~Hz}$ and $10^{-1} \mathrm{~Hz}$, at the open circuit potential $\mathrm{E}_{\mathrm{ocp}}$ with a disturbance of $10 \mathrm{mV}$. The Nyquist diagrams show towards the high frequencies a semicircle characteristic of a transfer process and at lower frequencies the straight lines almost parallel to imaginary axis, which are characteristic of a blocking process. The diameter of the semicircle increases upon the addition $\mathrm{TiO}_{2}$ concentration of $10^{-4}$ to 
$10^{-3} \mathrm{M}$, value from which it gets dropped. This suggests that the film becomes increasingly capacitive and less conductive at low contents of $\mathrm{TiO}_{2}$, becomes increasingly conductive and less capacitive, indicating that to the high contents of $\mathrm{TiO}_{2}$ the film becomes more conductive.

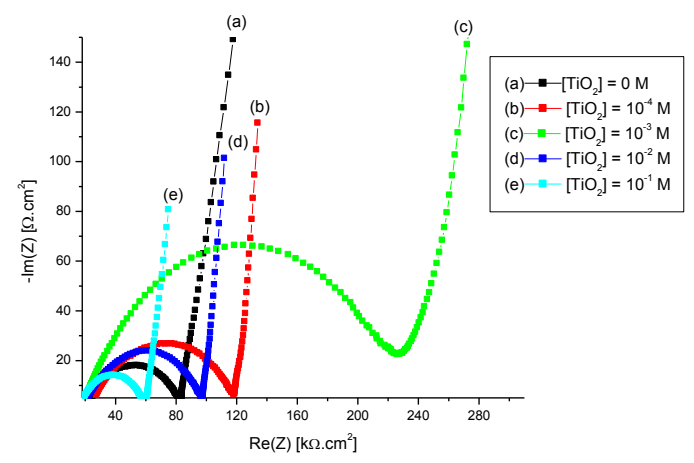

Figure 3: Nyquist diagrams relating to the $\left(\mathrm{PAn}+\mathrm{TiO}_{2}\right) / \mathrm{Pt}$ films in a solution free of monomer $\mathrm{H}_{2} \mathrm{O} /\left(\mathrm{LiClO}_{4} 0.1 \mathrm{M}+\mathrm{H}_{2} \mathrm{SO}_{4}\right.$ $0.5 \mathrm{M})$, recorded on a frequencies range between $10^{5} \mathrm{~Hz}$ and $10^{-1} \mathrm{~Hz}$, at the open circuit potential, with a disturbance of 10 $\mathrm{mV}$. The film is obtained from solutions containing different concentrations of titanium oxide.

\section{4) Characterization of the composite $\left(\mathbf{P A n}+\mathrm{MnO}_{2}\right)$}

The figure 4 shows the impedance measurement spectroscopy diagrams relating to the composite material (PAn + $\left.\mathrm{MnO}_{2}\right) / \mathrm{Pt}$ obtained from an aqueous solution $\left(0.5 \mathrm{M} \mathrm{H}_{2} \mathrm{SO}_{4}+0.1 \mathrm{M} \mathrm{LiClO}_{4}\right)$, containing the aniline as monomer and manganese oxide. The latter is held in suspension by stirring. The film is obtained for different concentrations of manganese oxide. The curves were recorded on a frequency range between $100 \mathrm{kHz}$ and 100 $\mathrm{mHz}$, at the open circuit potential $\mathrm{E}_{\mathrm{ocp}}$, with a disturbance of $10 \mathrm{mV}$.

The Nyquist diagrams show to a high frequencies arc characteristic of a charge transfer process and to lower frequencies the straight lines almost parallel to imaginary axis, which are characteristic of a blocking process. The diameter of the semicircle increases with the addition of $\mathrm{MnO}_{2}$ from the concentration of $10^{-3} \mathrm{M}$ to $10^{-2} \mathrm{M}$, value from which it gets dropped. This suggests that the film, it becomes increasingly less conductive and capacitive for low concentrations of $\mathrm{MnO}_{2}$, becomes increasing less conductive and capacitive for concentrations higher than $10^{-3} \mathrm{M}$. This shows that to the high concentrations of $\mathrm{MnO}_{2}$ film becomes conductive.

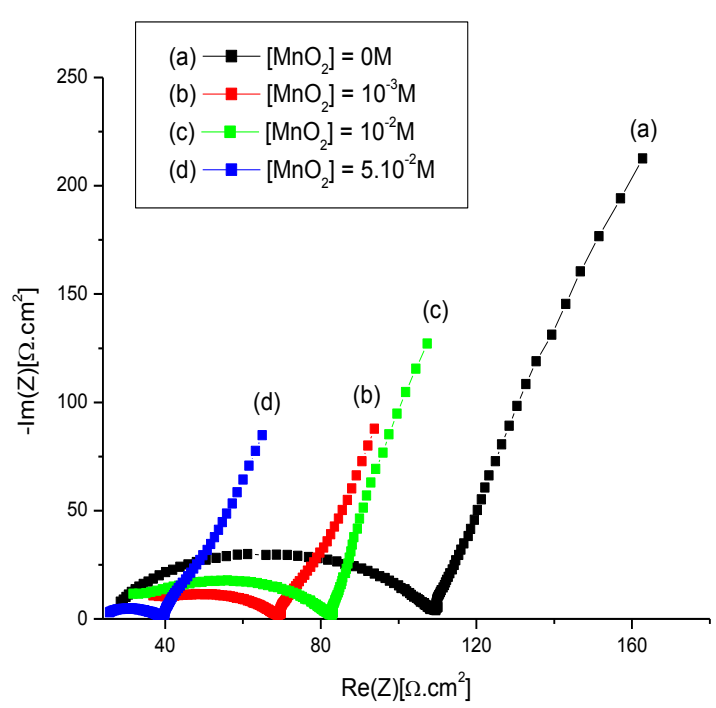

Figure 4: Nyquist diagrams related to the films of composite $\left(\mathrm{PAn}+\mathrm{MnO}_{2}\right) / \mathrm{Pt}$, obtained for different concentrations of $\mathrm{MnO}_{2}$, indicated on curves, analyzed in a solution containing no monomer and $\mathrm{MnO}_{2}$.

\section{Conclusion}

Analysis of the electrochemical properties of the polyaniline obtained on platinum, or on powders of manganese oxide or titanium oxide was carried out by cyclic voltammetry and impedance measurement spectroscopy.

The study shows that these molecular materials, modified or not, by doping or by incorporation of oxide 
semiconductors, possess high performance which allows them to be used as active electrode materials in generators or in the design of components electronics such as lights emitting diodes and the field effect transistors.

The polymers can be localized electroactive sites obtained by incorporation of oxide semi conductor in polyaniline could also be applied as composite materials for electrocatalysis and electrochemical generators. Indeed, it was also shown during this work that the charge/discharge curves of electrodes $\mathrm{PAn} / \mathrm{MnO}_{2}$ show excellent potential and very high yields coulombics in aqueous or organic mediums.

\section{References}

[1] K. Gurunathan, D.P.Amalnerkar, D.C.Trivedi, Matérials letters 57 (2003) 1642-1648

[2] M. Boopathi, M-S. Won, Y. H. Kim. S. C. Shin, Y-B Shim, Journal of the Electrochemical Society, 149 (7) E265-E271 (2002)

[3] Sondes Bourigua, Sarra El Ichi, Hafsa KorriYoussoufi, Abderrazak Maaref, Serge Dzyadevych,

Nicole Jaffrezic Renault, Biosensors and Bioelectronics 28 (2011) 105- 111

[4] Júlia C. Fatuch, Mauro A. Soto-Oviedo, César O. Avellaneda, Marcos F. Franco, Wanderson Romão, Marco-A. De Paoli, Ana Flávia Nogueira, Synthetic Metals 159 (2009) 2348-2354

[5] R. Hajlaoui, D. Fichou,, G. Horowitz, B. Nessark, M. Constant, and F. Garnier, Adv. Mater. 9 (1997) No7

[6] K. Rajendra Prasad, N. Munichandraiah, J. Electrochem. Soc., 149 (2002) A13

[7] D. Hertel, H. Bassler, U. Scherf, H. H. Horhold, J. Chem. Phys. 110 (18), 9214 (1999). 